\title{
DESENVOLVIMENTO DE SISTEMA EXCLUSIVO COM CONCEITOS BIM ATRAVÉS DE PLUGIN DO SOFTWARE SKETCHUP: GESTÃO EM PROCESSOS DE INDÚSTRIA DE DIVISÓRIAS ${ }^{1}$
}

\author{
EXCLUSIVE SYSTEM DEVELOPMENT WITH BIM CONCEPTS THROUGH \\ SOFTWARE PLUGIN SKETCHUP: MANAGEMENT IN PARTITIONS \\ INDUSTRY PROCESSES
}

\author{
Leandro dos Santos Magalhães \\ Equipe B Arquitetura, Design e Multimídia, UFMG, UNIBH \\ leandro@equipeb.com \\ Fernando Pacheco do Nascimento \\ Equipe B Arquitetura, Design e Multimídia, UFMG \\ fernando@equipeb.com
}

\begin{abstract}
Resumo
Este trabalho aborda uma ferramenta computacional, para a produção de projetos de constituição de ambientes corporativos com o uso de divisórias. Tal ferramenta exclusiva apropria-se de alguns conceitos de Building Information Modeling (BIM) ao dotar a indústria responsável de um sistema capaz de convergir informações do projeto e do processo industrial simplificando meios originalmente empregados. Esta ação destaca-se por ter sido concretizada a partir do acréscimo de novas funções ao software pré-existente, Sketchup, através do desenvolvido plugin. O software resultante encurta o processo de desenho e permite que sejam produzidos ambientes com poucos cliques. O resultado projetual já se apresenta com boa qualidade de visualização tridimensional. Os componentes digitais deste projeto são parametrizados e por isso é a partir da representação 3D que são exportados o orçamento preciso para a implantação do projeto, imagens "fotorrealísticas", que facilitam a sua compreensão por leigos e principalmente os outros documentos que orientam o processo industrial no que tange a produção, estocagem, e montagem das peças. Esta ação pertence ao projeto "Plataforma visual 3D com banco de dados georreferenciado para gestão completa de infraestruturas", realizado com o apoio do Conselho Nacional de Desenvolvimento Científico e Tecnológico, CNPq no edital, RHAE mestres e doutores na empresa.
\end{abstract}

Palavras-chave: Sketchup. Plugin. Divisórias. BIM. Indústria.

\begin{abstract}
This paper addresses a computational tool for producing enterprise environments projects with the use of partitions. This unique tool takes ownership of some concepts of Building Information Modeling (BIM) to provide the industry responsible for a system capable of converging project information and simplifying the manufacturing process originally employed. This action stands out for having been achieved from the addition of new functions to the pre-existing software, SketchUp, developed through the plugin. The resulting software shortens the design process and enables spaces to be produced with a few clicks. The architectural design results already presented good quality of three-dimensional visualizations. The digital components of this three-dimensional representation are parameterized so is from the $3 D$ representation are exported, the precise budget for the project
\end{abstract}

\footnotetext{
${ }^{1}$ MAGALHÃES , Leandro; NASCIMENTO, Fernando. DESENVOLVIMENTO DE SISTEMA EXCLUSIVO COM CONCEITOS BIM ATRAVÉS DE PLUGIN DO SOFTWARE SKETCHUP: Gestão em processos de indústria de divisórias. In: ENCONTRO BRASILEIRO DE TECNOLOGIA DE INFORMAÇÃO E COMUNICAÇÃO NA CONSTRUÇÃO, 7., 2015, Recife. Anais... Porto Alegre: ANTAC, 2015.
} 
implementation, pictures "photorealistic" that facilitate their understanding by lay people, and especially other documents that guide industrial process regarding the production, storage, and installation of parts. This action belongs to the project "3D visual platform with georeferenced database for complete management infrastructure" held with the support of the National Scientific and Technological Development Council, CNPq in the announcement, RHAE masters and doctors in the company.

Keywords: Sketchup. Plugin. Partitions. BIM. Industry.

\section{INTRODUÇÃO}

Neste trabalho serão observados aspectos do desenvolvimento e da estrutura computacional (MCCONNELL, 2004) da ferramenta na qual a representação gráfica em 3D de um projeto de arquitetura é o input do sistema que coordena a produção dos componentes de um sistema construtivo de divisórias de ambientes. Uma solução similar às características do Building Information Modeling, BIM (Modelagem da Informação da Construção).

A indústria do ramo de divisórias especiais, aqui denominada Indústria-A, comercializa os componentes e a instalação de um sistema estrutural de divisórias voltado para segmentar áreas livres, como andares corridos para empresas.

Existem muitos tipos de divisórias no mercado. Ao definir seu produto como "divisórias especiais", a Indústria-A estabeleceu um recorte, focado em clientes que procuram o estabelecimento de um espaço físico com melhores qualidades ambientais e estéticas. $\dot{E}$ por esse motivo que esse sistema construtivo é também mais complexo, apresentando materiais de estrutura tão refinados quanto os de acabamento, além de incorporar elementos voltados para o equilíbrio térmico e acústico nos ambientes.

Figura 1 - Tipos de divisórias. a) Divisória simples b) Divisória especial
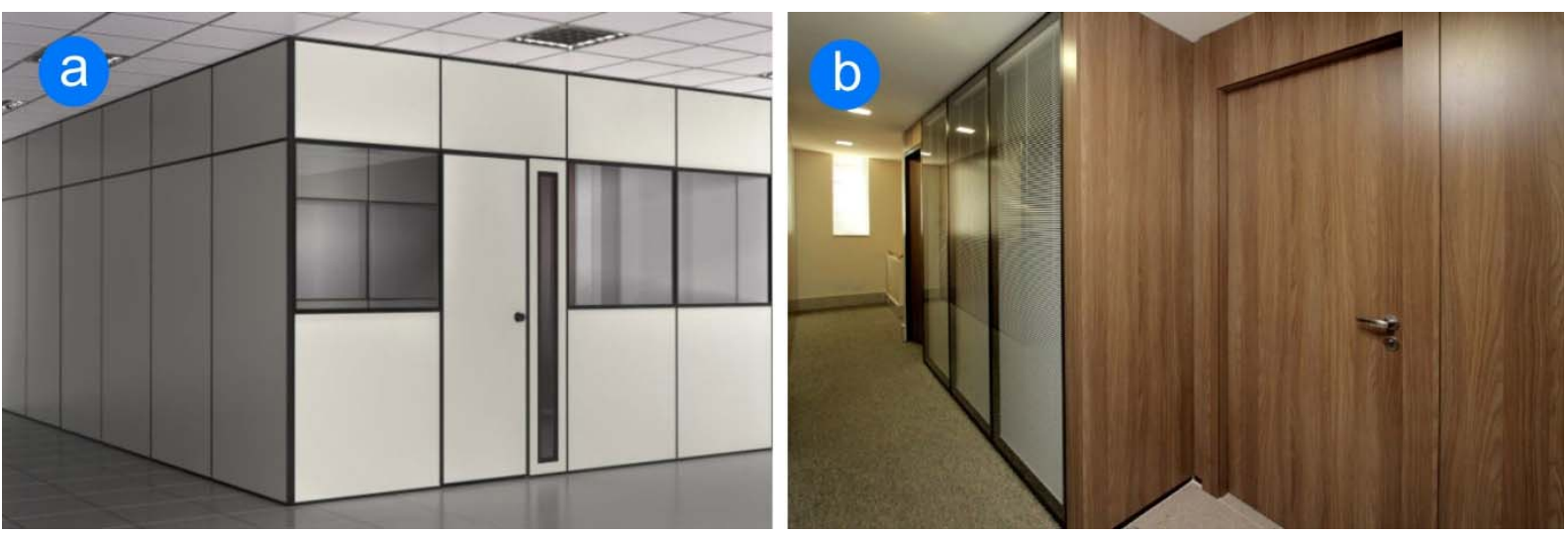

Fonte: Acervo da Indústria-A

Tal complexidade deste sistema estrutural reflete-se diretamente nos processos internos da indústria, que ocorrem entre o momento em que o cliente apresenta a demanda e quando o produto é finalmente instalado no local. Estes processos devem responder às determinações impostas pelo processo industrial, relativo ao corte de peças, estocagem de matéria prima, e paralelamente o projeto arquitetônico deve também estar em consonância com tais determinações.

O sistema estrutural apresenta-se, quando finalizado, em paredes de 90 milímetros de espessura estruturadas com componentes metálicos modulados na vertical e horizontal, e com vedações em vidro ou madeira, ambas com opções de acabamentos. Os principais componentes verticais são os montantes, que determinam a modularização visível da 
parede. Estes apoiam-se no chão dentro de perfis metálicos tipo $C$, denominados guias de piso, o mesmo que ocorre no topo com as guias de teto. Quando há modularizações também na vertical, são colocadas peças metálicas intermediárias.

O catálogo de produtos oferece centenas de tipos de divisórias que, se contadas as possibilidades de variações com os materiais e modularizações disponíveis, chegam a milhões de combinações.

O sistema computacional abordado buscou unificar os processos industriais, processos comerciais, catálogos e projeto arquitetônico, elemento central pois é a partir dele que são derivados os demais produtos.

\section{DELINEAMENTO DO PROBLEMA}

Quando a equipe de pesquisadores e técnicos da pesquisa do CNPq encontrou-se com os responsáveis pela Indústria-A, estes já tinham estruturado o problema enfrentado pelo seu negócio. O processo de comercialização de divisórias é lento, complexo e sujeito a erros, como digitação incorreta, falha na aplicação das metodologias de cálculo, erros de cálculos numéricos. Essa etapa atrasa e dificulta o trabalho da equipe de campo que transporta os componentes da indústria para montar as divisórias no local. O problema do tempo é crucial, principalmente para empresas que estão especificamente em tempos de mudança do espaço físico, afinal, durante as transições, além de fazer-se necessário um alto investimento, a empresa fica sujeita à diminuição da produtividade, gerando um ciclo perigoso. Assim, o quesito tempo é, de fato, uma variável na tomada de decisão do empresário que vai contratar a instalação das divisórias. Outro fator que gera frequentes atrasos no processo de vendas está no fato de o cliente muitas vezes não conseguir compreender exatamente o que está comprando. Isso se deve ao fato de que se emprega o desenho técnico como linguagem de comunicação, e o cliente, muitas vezes não habituado com a linguagem, se confunde. Além disso, a planta técnica exclui a possibilidade de visualização de uma série de parâmetros pelos quais o cliente está pagando, como os luxuosos acabamentos, vidros e persianas. Esses itens apenas podem ser vistos nos catálogos da empresa, exigindo do cliente a capacidade de se abstrair e imaginar como ficará o ambiente que está contratando. A ineficácia do processo gera dúvidas e hesitações. Mais tempo é gasto. Observando um sistema utilizado pelas indústrias de cozinhas planejadas, os empresários vislumbraram um sistema que poderia encurtar o processo de venda. Nesse ramo de negócio, os vendedores utilizam um software próprio, no qual a cozinha é modelada em 3D, e a visualização do cliente é facilitada, encurtando o processo de vendas. Como o campo de conhecimento requerido para a elaboração de um projeto similar coincide com o objeto de estudo da equipe do projeto Gestão 3D, foi estabelecido um acordo.

A Indústria-A forneceu a documentação relativa ao mapeamento dos processos internos, além de ter permitido o acompanhamento sistemático de todas as atividades relativas à venda de divisórias. As entrevistas e os dados coletados fornecem dados para a estruturação do sistema e das afirmações que seguem. Trata-se da construção de diagramas mostrando o fluxo da informação para cada ação executada no ambiente da empresa, similar à notação BPM. Esse fluxograma mostrou-se como um meio eficaz de comunicação entre clientes, arquitetos e desenvolvedores, por permitir a identificação de quais etapas podem ser abordadas por um software (CLEMENTS, PAUL 2010). Entre os documentos fornecidos pela Indústria-A, consta também o Manual de Montagem, fundamental para a obtenção dos relatos deste trabalho. A Figura 2 mostra um tipo de linguagem eficiente no mapeamento das funções que passaram a ser desempenhadas pelo sistema. 
Figura 2 - Documentação de parte dos processos comerciais adotados pela Indústria-A

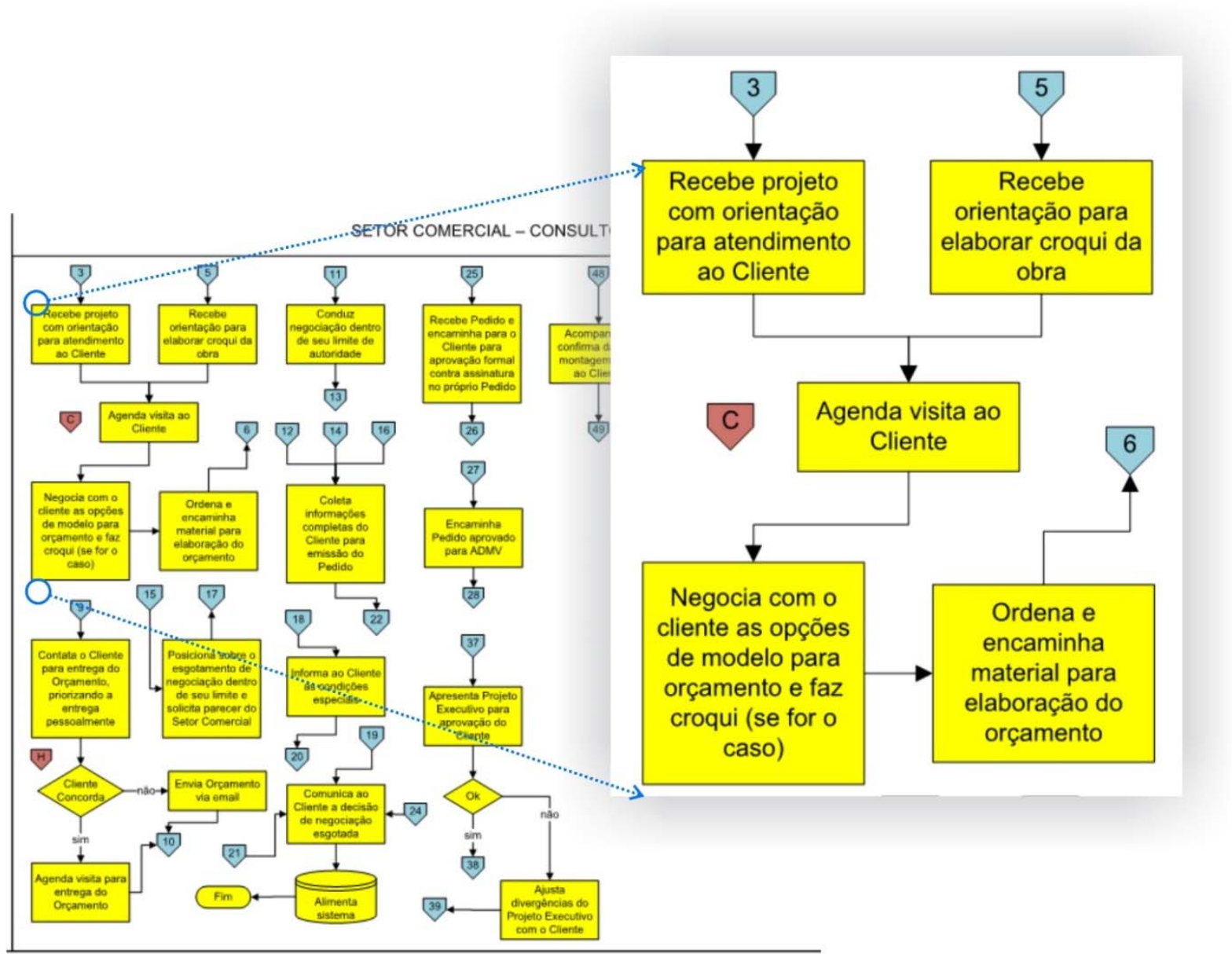

Fonte: Acervo da Indústria-A

O processo de venda das divisórias possui o seguinte fluxo de informação:

1) Abordagem do cliente: Os clientes que procuram os serviços da Indústria-A são, em geral, corporações e empresas bem estruturadas que procuram o estabelecimento de suas sedes e escritórios dentro de edifícios comerciais. Quando procuram a empresa, já estão interessados no acabamento que oferece e, normalmente, conforme entrevista com os empresários, já possuem um projeto contratado de um arquiteto. Esse projeto é o input inicial de dados, e o primeiro produto solicitado a partir desse input é o orçamento para execução daquele projeto com o sistema de divisórias.

2) Quando chega à indústria, o desenho técnico do arquiteto é refeito seguindo as lógicas de modulação da empresa. O tamanho dos módulos precisa ser cuidadosamente definido, a fim de que sejam contempladas todas as inúmeras peculiaridades do processo industrial de produção das peças. Esse novo desenho é uma planta técnica que contém a mesma divisão espacial fornecida pelo arquiteto, revelando a divisão em módulos que será usada, e com uma legenda que remete cada módulo a um tipo de divisória do catálogo. 
Figura 3 - Projetos para divisórias

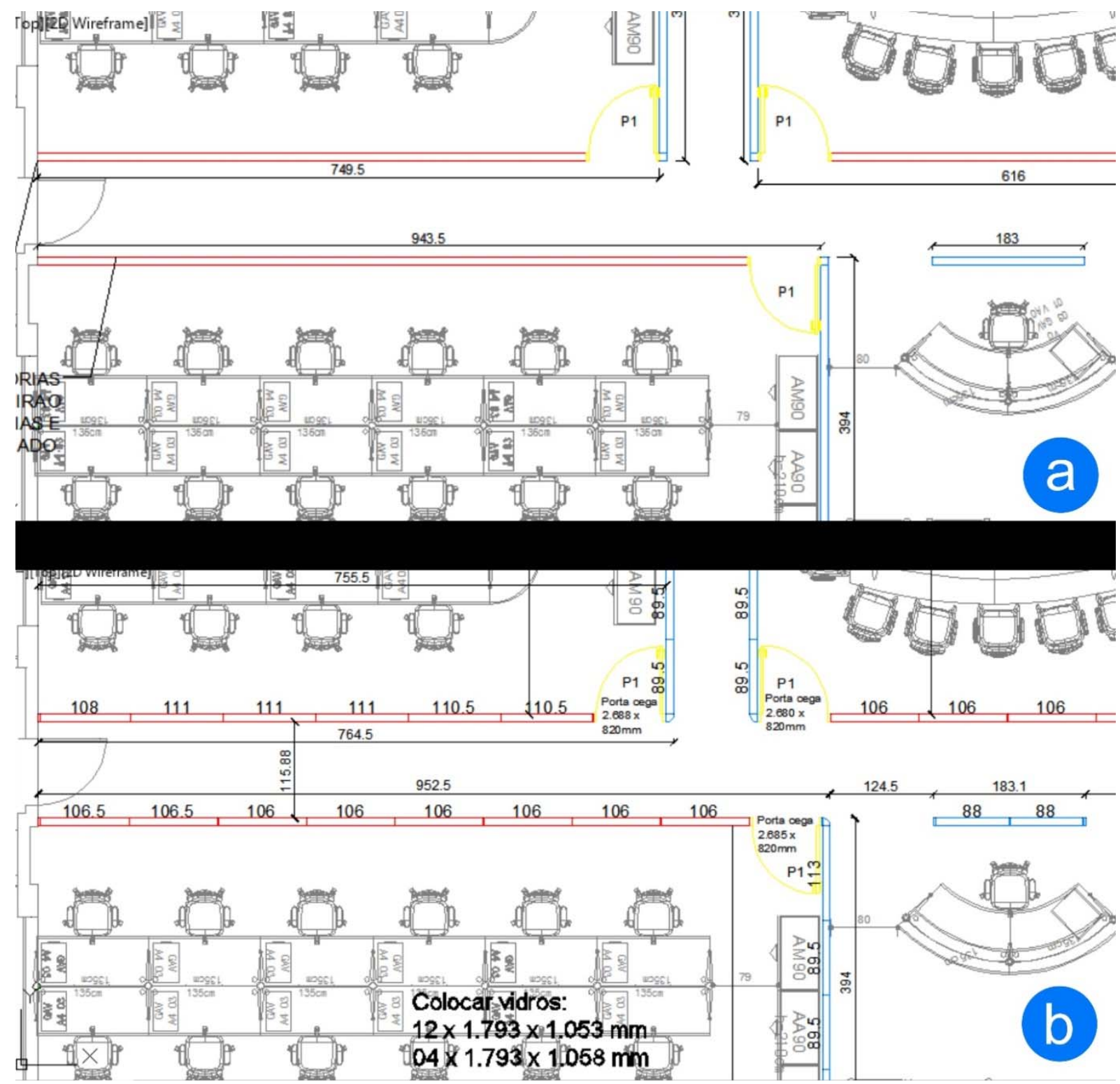

Fonte: Projetos cedidos pela Indústria-A. Montagem elaborada pelo autor. a) Projeto elaborado pelo cliente b) Projeto refeito pela empresa seguindo as normativas internas já revelando a modularidade das paredes em linhas vermelhas.

3) Mediante aprovação do projeto pelo cliente, o próximo passo é dado para a elaboração do orçamento. Munido de papel, calculadora simples e lápis, um funcionário da empresa calcula as áreas de elevação de cada tipo de divisória, levando em consideração as medidas horizontais que obtém no software de desenho técnico - CAD, e o pé direito fornecido pelo cliente. Todas as áreas são somadas, adotam-se os procedimentos determinados pela empresa e é multiplicado pelo preço unitário da área de cada tipo de divisória. Itens especiais, como portas, são contados individualmente e também possuem preços unitários, sendo, portanto, adicionados à conta. Calcula-se ainda, também manualmente, a quantidade de Lã de Rocha2 que corresponde ao pedido. Esse produto

\footnotetext{
${ }^{2}$ A Lã de Rocha é um tipo de isolante fibroso que, ao ser empregado no vão das divisórias, aprimora sua inércia térmica e absorção acústica, melhorando o conforto ambiental no ambiente em que é utilizada.
} 


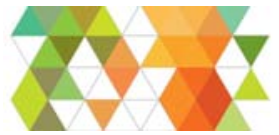

é adquirido em sacos, cada um contendo uma quantidade determinada. O cálculo da quantidade de lã de rocha precisa não apenas prever a quantidade de lã, mas a quantidade otimizada de pacotes de lã de rocha que devem ser levados à instalação. Como quantidade otimizada entenda-se a consideração de restos de um pacote de lã de rocha para iniciar o preenchimento de outra área do projeto. Assim, áreas de tipos de divisórias, portas e lã de rocha são os itens medidos que irão determinar o preço da aquisição dos produtos e serviços de instalação das divisórias.

4) Quando o orçamento não é aprovado, o trabalho é descartado. Caso contrário, a aprovação do orçamento dispara o processo na Indústria-A denominado Empenho. Esse procedimento visa à preparação do almoxarifado para a entrada do serviço na linha de produção. Algumas peças são reservadas e outras precisam ser adquiridas para atendimento da demanda. Essa etapa impede que a sobreposição de serviços gere crises de esgotamento do estoque. A etapa de empenho exige a atuação criteriosa de funcionário experiente na empresa, que conheça não apenas a metodologia da composição do documento de empenho, mas aspectos da natureza industrial, pois nessa fase é necessário que decisões sejam tomadas. Partindo do projeto que gerou o orçamento, o procedimento de empenho irá estabelecer um quantitativo preliminar de cada uma das milhares de peças que podem compor esse sistema construtivo. $O$ procedimento ocorre de forma segmentada, com etapas de medição no software tipo $\mathrm{CAD}$, contagens manuais com papel e lápis e preenchimento de uma tabela com cálculos automáticos que gera parte dos resultados esperados. Conforme levantado no acompanhamento e nas entrevistas na Indústria, o funcionário responsável chega a gastar de meio turno a um dia de trabalho apenas confeccionando uma lista de empenho.

5) O empenho garante que as peças estarão no estoque para serem cortadas e adequadas ao projeto. No entanto, o projeto fornecido estava até esse ponto baseado nas informações fornecidas pelo cliente. Esse tipo de sistema construtivo, por conter partes industrializadas pré-produzidas na fábrica, é detalhado em milímetros. Assim, faz-se necessário que a própria indústria realize as medições no local para adequação do projeto à sua metodologia industrial. A aferição de medidas busca identificar desníveis de piso, irregularidades nos forros e paredes e medidas precisas do espaço físico. Esse levantamento gera um novo projeto, mais detalhado. Para a elaboração desse projeto, não se apresentou como vantajoso o aproveitamento dos desenhos e cálculos anteriores, portanto tudo é refeito. Inclusive a etapa Empenho precisa ser refeita agora sob o nome Quantitativos, já que com maiores detalhes estabelece as instruções finais para cortes, compras e separação de peças.

Esse é o conjunto de ações apresentadas pelos empresários como etapas cruciais de seu negócio sobre as quais gostariam de realizar melhorias mediante o desenvolvimento de um sistema exclusivo.

\subsection{Conceito do sistema computacional}

O sistema proposto para abordar a situação relatada buscou basear-se no desenho como ferramenta central, uma vez que dele podem ser extraídas as informações para orçamento e empenho automaticamente. E nessa etapa que pode-se gerar o encurtamento dos processos, mantendo um melhor aspecto qualitativo das soluções.

A exemplo do referencial teórico, o sistema baseou-se no desenvolvimento de um plugin, mais uma vez, do Sketchup. O software original obtém, conforme demonstrado, grandes êxitos na conquista de público, tendo estabelecido marcos de interação humano-computador com modelos tridimensionais. Desse programa foram aproveitadas as capacidades de 
visualização, manipulação e construção de modelos 3D, além da funcionalidade "componentes dinâmicos", que já prevê certa parametrização de entidades do modelo.

A seguir, serão detalhados os aspectos cabíveis das funcionalidades do sistema que foi desenvolvido.

\section{SISTEMA DESENVOLVIDO}

O sistema proposto encontra-se estruturado da seguinte forma: uma vez instalado, aparece na interface do Sketchup com três botões próprios. O primeiro deles permite a escolha do tipo de divisória que se deseja utilizar. É aberta uma janela, e nela é escolhido o modelo de divisória. Completadas as configurações, o usuário desenha as paredes seguindo as orientações oriundas, assim como no processo original, do projeto fornecido pelo cliente. Para desenhar uma parede, foi desenvolvida uma nova função, aprimorando a função original de desenho do software. Ao clicar em um ponto da tela, já é exibida a espessura da parede de maneira e o segundo clique define seu comprimento. Com o segundo clique já surge a parede modulada pelas divisórias. Essa parede é composta por componentes dinâmicos, que são entidades em 3D as quais contêm parâmetros que coordenam o método de escala dos objetos, impedindo deformações e tamanhos incoerentes com a produção da indústria.

Figura 4 - Visualização 3D do projeto utilizando o sistema construtivo de divisórias construído a partir do plugin demonstrado.

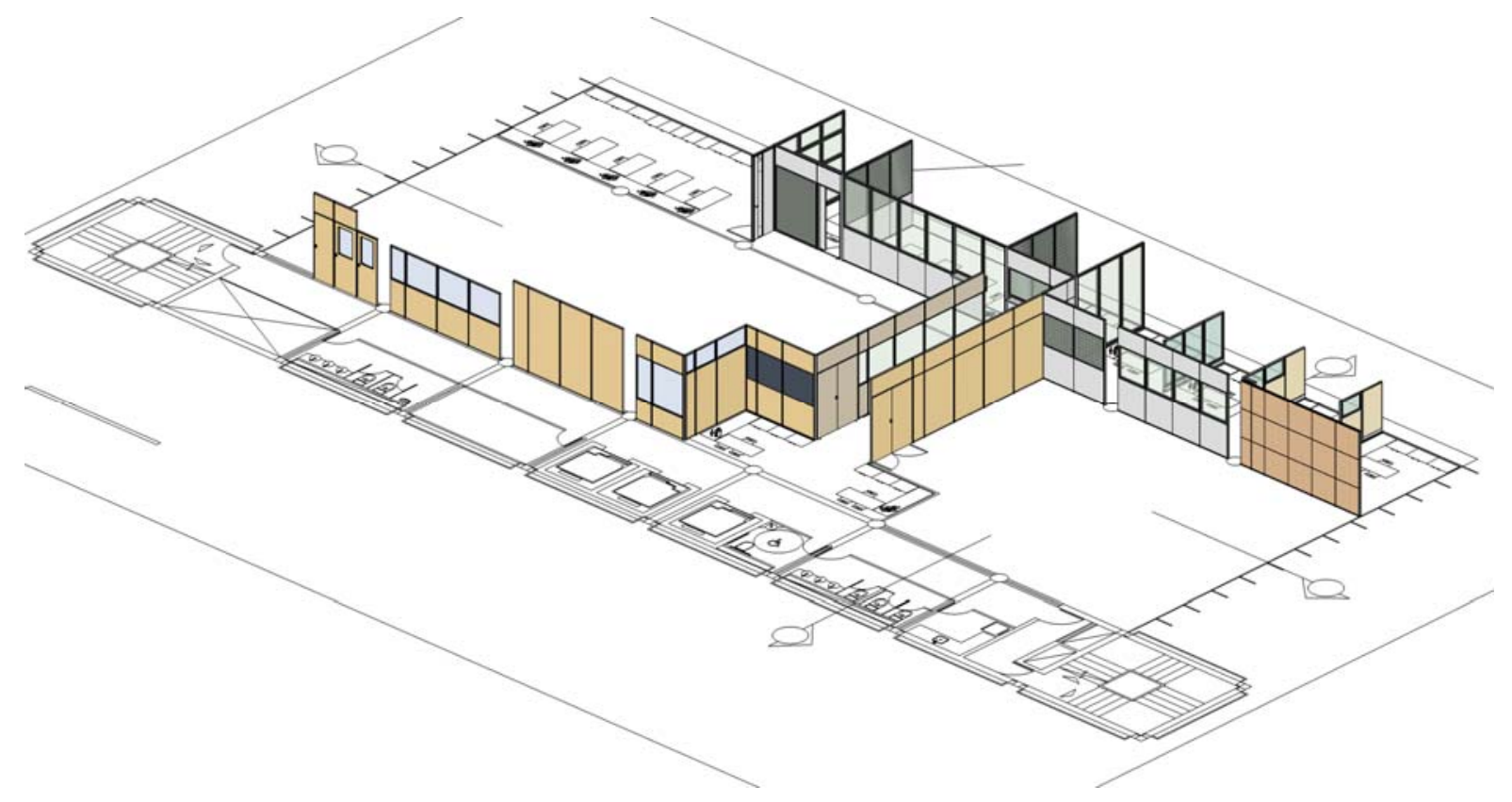

Fonte: Elaborado pelo autor. Sob a imagem encontra-se o desenho técnico que orienta o projeto 
Figura 55 - Componente dinâmico.

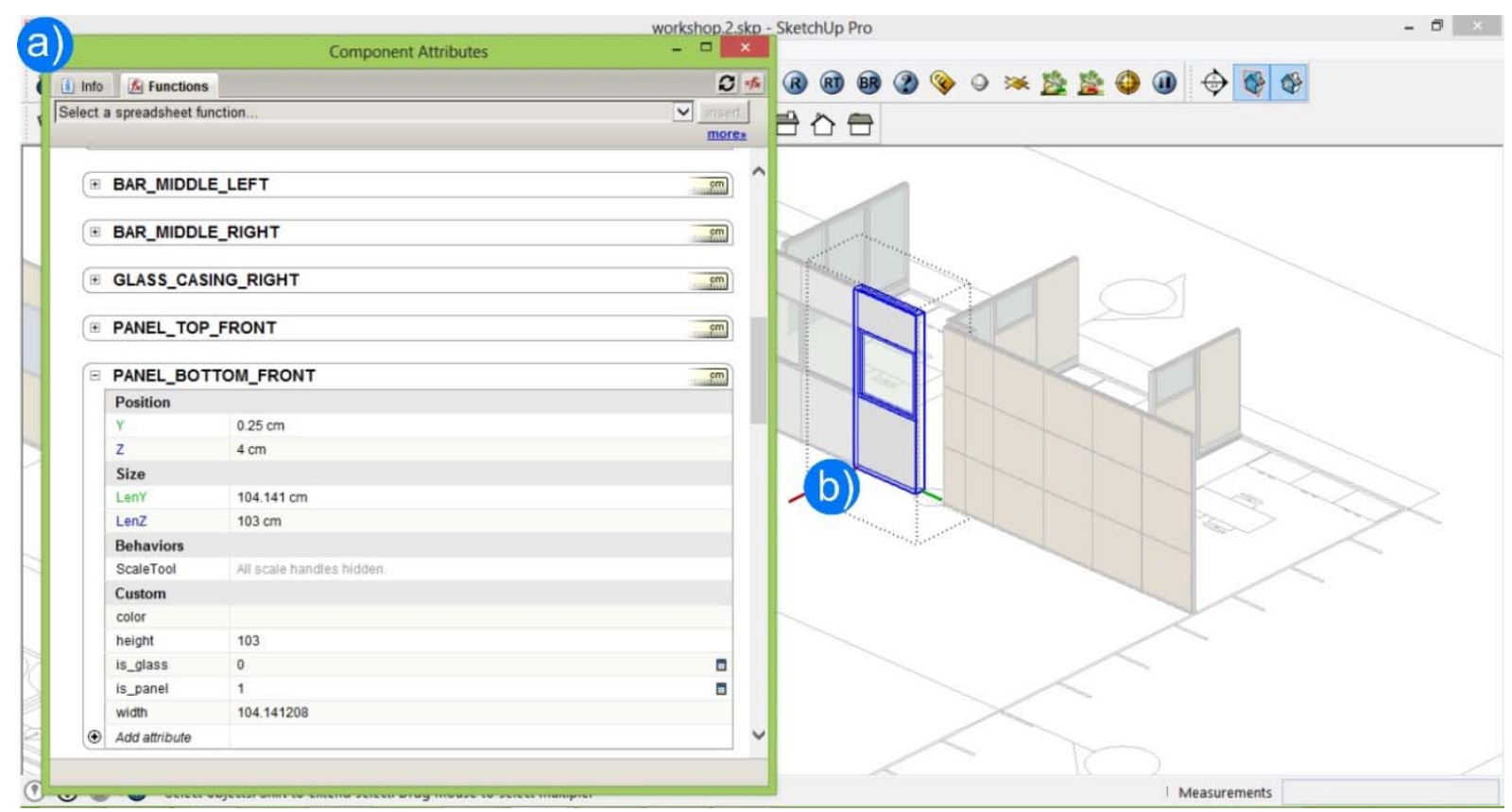

Fonte: Elaborado pelo autor. a) Mostra a janela de atribuições de parâmetros dinâmicos aos componentes de um único módulo de divisórias. Os parâmetros visíveis na imagem referem-se às dimensões do painel de madeira frontal inferior. b) Mostra a entidade do modelo, módulo único de divisória, que tem os parâmetros exibidos.

O modelo resultante contém parâmetros que alimentam as funções de orçamento e empenho, respectivamente, os dois outros botões na interface do software. Desse modo, ao clicar sobre orçamento, o sistema já fornece em segundos o cálculo de áreas, produtos unitários, lã de rocha, e multiplica os devidos fatores, gerando o documento de orçamento. Para isso, o método computacional utilizado foi a criação de um objeto JSON3 que, a grosso modo, traduz um objeto tridimensional em linguagem de texto, para então ser aproveitada por linguagens computacionais (HUNT, 1999). No objeto JSON, incluem-se, por exemplo, metragem dos componentes das divisórias, materiais de acabamento, preço e quaisquer parâmetros que tenham sido determinados nas etapas anteriores. Esse objeto é requisitado pelo servidor PHP4 que os processa, passando pelas fórmulas que remetem à metodologia de trabalho da indústria, como contenção do tamanho de peças de madeira, relação com peças remanescentes no estoque, definição de ferramentas que precisam ser levadas à obra para instalação dos componentes que serão empregados. Essas informações que irão compor, enfim, os documentos de orçamento e empenho, gerados automaticamente. São inseridas no documento as miniaturas de cada tipo de produto orçado, favorecendo a visualização pelo cliente. Para cooperação entre os diferentes recursos computacionais e sua exibição em interfaces no lado do cliente, utilizou-se o recurso Bootstrap, que será detalhado à frente.

Do mesmo modelo 3D do qual são extraídos dados de orçamento, é extraída uma

\footnotetext{
3 JavaScript Object Notation, é um formato leve para intercâmbio de dados computacionais. JSON é um subconjunto da notação de objeto de JavaScript, mas seu uso não requer JavaScript exclusivamente. (Wikipedia)

${ }^{4}$ PHP (um acrônimo recursivo para "PHP: Hypertext Preprocessor", originalmente Personal Home Page) é uma linguagem interpretada livre, usada originalmente apenas para o desenvolvimento de aplicações presentes $e$ atuantes no lado do servidor, capazes de gerar conteúdo dinâmico na World Wide Web. (Wikipedia)
} 


\section{TIC2015}

renderização, processo digital que, a partir do posicionamento de uma câmera em um modelo 3D, permite obter uma imagem fotorrealística da cena devido à parametrização dos materiais, que passam a representar comportamentos do mundo físico, de reflexo, transparência e reações à luz. Essa possibilidade de produção de imagens fotorrealísticas dos projetos tornou-se um poderoso instrumento de vendas, já que favorece a compreensão rápida do cliente. O recurso é largamente utilizado pelo mercado imobiliário.

Figura 6 - Imagem renderizada a partir dos modelos paramétricos

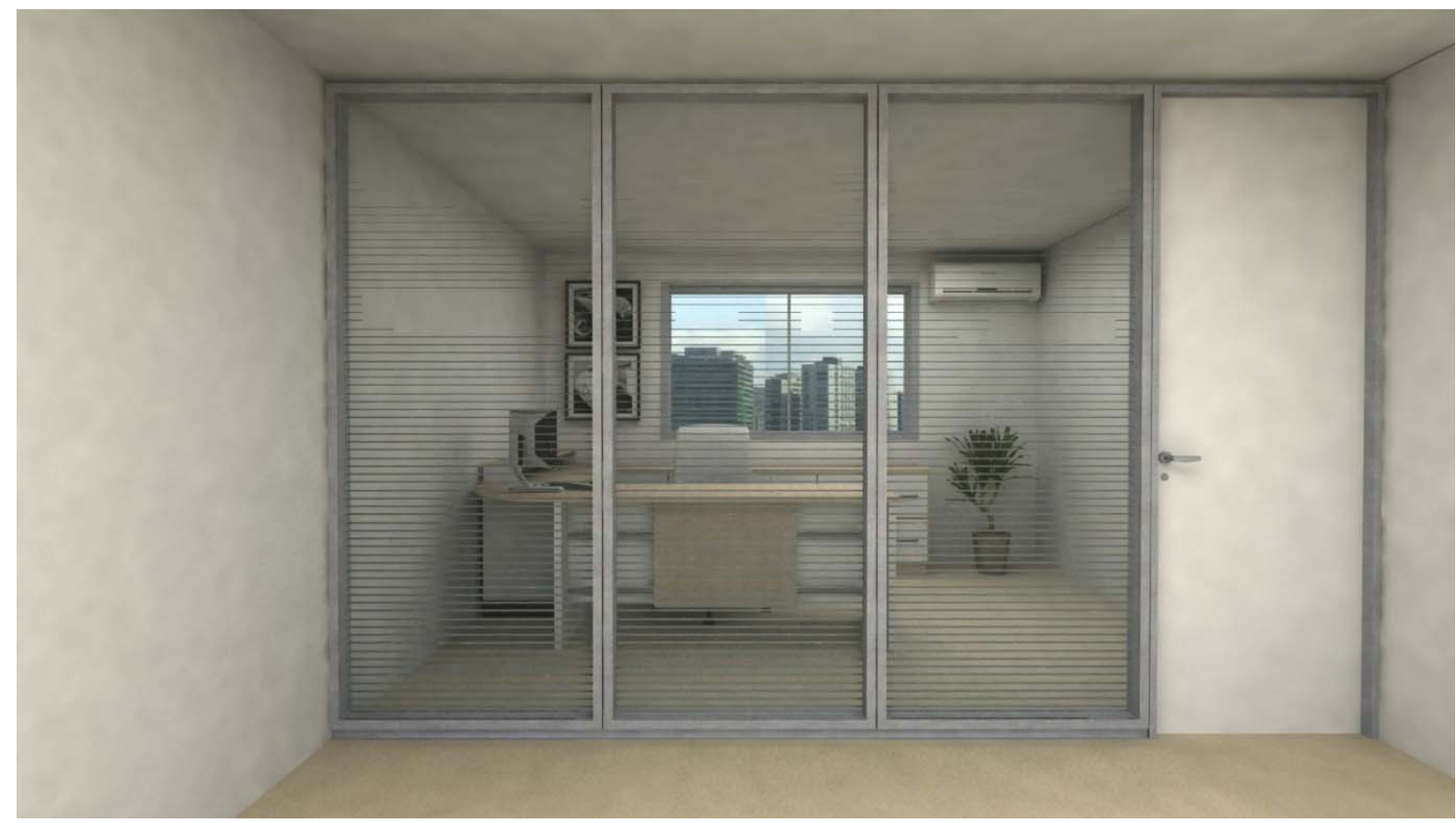

Fonte: Acervo da Indústria-A

Com a aprovação do cliente ocorrendo de forma mais fluida, o processo de empenho é acionado. Mais uma vez, um único clique gera a documentação detalhada do empenho e, para obtenção do quantitativo, basta atualizarem-se as medidas e a função empenho que, agora com dados mais precisos, gera detalhadamente as quantidades de materiais que serão gastos naquele projeto. 
Figura 7 - Alguns tipos de divisórias abordados no sistema
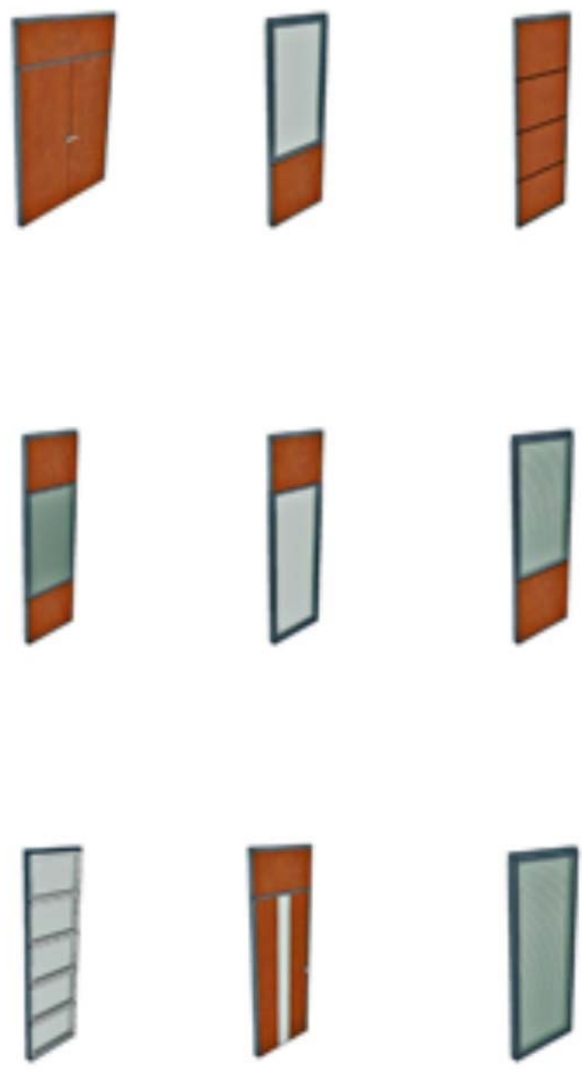

Fonte: Acervo da Indústria-A

A forma de representação do espaço buscou aprimorar a interação já suficiente que o Sketchup provê. Selecionado e configurado o tipo de divisória a ser empregado, ao clicar em um ponto da tela, sendo este a origem e o ponto de inserção da divisória, já se visualiza a espessura da parede no desenho, ou seja, um paralelogramo de espessura fixa, de 90 centímetros, relativa à espessura da divisória e com o comprimento a ser determinado pelo clique seguinte, limitando-se o tamanho da parede.

O programa irá, então, calcular como dividir aquela parede em módulos do tipo de divisória escolhido e ainda obedecendo aos parâmetros da indústria, como tamanhos mínimos e máximos das peças, e cálculos de contenção de desperdícios.

O resultado se apresentará com visualização em três dimensões, moduladas, em cores. Clicando-se sobre os módulos com o botão direito, é obtida a janela de escolha de materiais de acabamento entre 80 tipos de acabamento de madeira e uma dúzia de acabamentos para vidro, com películas. É dessa representação tridimensional que são derivados os já mencionados documentos relativos a orçamento, empenho e quantitativo final de peças, além da imagem fotorrealística do ambiente comercializado, favorecendo a compreensão prévia do produto adquirido pelos clientes da indústria. 


\section{标:}

\section{CONCLUSÕES}

Este trabalho revelou a tradução de processos manuais adotados por uma indústria do ramo de divisórias, inclusive o processo de projeto arquitetônico, em um sistema computacional com características do sistema BIM. Esta mudança gerou maior agilidade entre o surgimento da demanda e a instalação final das divisórias uma vez que toda documentação que orienta produção de peças e venda das mesmas passou a ser derivada automaticamente do projeto arquitetônico. O processo de projeto também foi repensado, já que cada parede de divisórias passou a ser construída com dois cliques. Esta forma de interação humano-computador (ROGERS, Y; SHARP, H; PREECE 2013), é um meio de democratização da linguagem de projeto arquitetônico ao passo que a representação do espaço em três dimensões, e com as devidas representações gráficas que remetem aos materiais de acabamento, são uma forma de comunicação superior quando comparadas aos desenhos técnicos tradicionais anteriormente utilizados nos processos manuais da indústria.

Apesar de tratar-se de um produto da computação, o processo de desenvolvimento de software relatado por este trabalho foi coordenado por arquitetos. Esta experiência coloca a participação do arquiteto como central no desenvolvimento de sistemas computacionais que abordem questões espaciais. O profissional da arquitetura deve atuar no desenvolvimento da ferramenta tecnológica, ampliando não apenas o seu campo, mas introduzindo o pensamento espacial em outros campos do conhecimento. Mostrou imprescindível não apenas a presença do arquiteto, mas a composição de equipes transdisciplinares, com arquitetos, desenvolvedores, designers, e profissionais que possam contribuir de acordo com a temática abordada. Ao mesmo tempo, verificou-se que o vocabulário do arquiteto no trato do espaço é contributivo nesse quesito específico que tange à representação. Está reforçada a posição de que programas de computador desenvolvidos por equipes compostas apenas de engenheiros de software estão fadados ao fracasso pois este profissional pode não abordar as questões espaciais com a mesma fundamentação (NELSON,1990).

O tipo de documentação gerada, em função da adoção de alguns recursos BIM, mostrou atender corretamente à precisão demandada na geração de orçamentos assim como na geração das instruções para cortes e separação de peças na planta industrial sendo naturalmente mais ágil que o processo manual e gerando produtos continuamente atualizados com as informações fornecidas pela empresa, como preço unitário, quantidade de estoque, entre outros.

\section{AGRADECIMENTOS}

Agradecemos à EquipeB, à Ampla Divisórias Especiais, à UFMG, ao UNI-BH.

\section{REFERÊNCIAS}

BOOTSTRAP. Disponível em: <http://getbootstrap.com/>. Acesso em: 20 de maio de 2013.

CLEMENTS, PAUL et al. Documenting software architectures: views and beyond. 2.ed. Pittsburgh: Addison-Wesley Professional, 2010.

HO, CLARENCE; HARROP, Rob. Pro spring 3: a comprehensive reference and practical guide to the spring framework. New York: Apress, 2012.

HUNT, Andrew; THOMAS, David. The pragmatic programmer: from journeyman to master. Pittsburgh: Addison-Wesley Professional, 1999.

jQuery. Disponível em: <http://jquery.com/>. Acessado em: 20 de abril de 2013. 
jQuery Grid Plugin - jqGrid. Disponível em: <http://www.trirand.com/blog//>. Acesso em: 23 de junho de 2013.

jQuery UI. Disponível em: <http://jqueryui.com/>. Acessado em: 20 de abril de 2013.

Manual do Sistema de divisórias Ampla. Belo Horizonte, 2014.

MCCONNELL, Steve. Code complete: A practical guide to software construction. 2.ed. Portland: Microsoft Press, 2004.

NBS National Bim Library. Disponível em: <http://www.nationalbimlibrary.com/>. Acessado em: junho de 2015.

NELSON, Theodore Holm. The Art of Human Computer Interface. Brenda Laurel ed., 1990.

ROGERS, Y; SHARP, H; PREECE, J. Design de Interação - Além da interação humanocomputador. Bookman, 2013.

SENGERS, P. et al. Culturally embedded computing. Pervasive Computing, IEEE, 2004, 3(1): 14.

SKETCHFAB. Disponível em: <https://www.sketchfab.com/>. Acessado em: junho de 2015.

SKETCHUP. Disponível em: <http://www.sketchup.com/>. Acessado em: junho de 2015.

Three.js - JavaScript 3d library. Disponível em: <http://threejs.org/>. Acessado em: 2 de abril de 2013. 